\title{
Una narrativa infantil y juvenil para la memoria
}

\author{
MARÍA BERMÚDEZ MARTÍNEZ \\ (Universidad de Granada)
}

\section{RESUMEN}

La problemática de la representación de la realidad histórica, política, social y la indagación en el pasado a través de una narrativa de la memoria, recorre varias de las literaturas hispanoamericanas actuales desde los años ochenta y noventa, y parece haber comenzado también su andadura en el ámbito de la literatura infantil y juvenil. Este artículo se propone como un acercamiento, incompleto sin duda - no se pretende la exhaustividad ante un panorama tan amplio y complejo, sino simplemente abordar algunas interesantes lecturas que van trazando una senda-, a los acercamientos que la narrativa infantil y juvenil hispanoamericana ha tenido hacia la realidad histórica y social y el tratamiento de la memoria, atendiendo especialmente al panorama argentino y poniendo a la vez sobre la mesa algunas de las cuestiones centrales en las que se debate la literatura infantil y juvenil en la actualidad.

Palabras clave: Literatura infantil y juvenil, memoria, América Latina, literatura argentina.

\section{ABSTRACT}

The issue of representation of the historical, political, social and inquiry in the past through a narrative of memory, go over a number of current Latin American literature since the eighties and nineties, and seems to have also started his career in the field of children's literature. This article is an approach, incomplete certainly - not completeness is intended to such a large and complex panorama, but simply tackle some interesting readings ranging drawing a track-, that children and young Hispanic narrative has to the historical and social reality and memory handling, with special attention to the Argentine scene and at the same time putting on the table some of the central issues in which children's literature is discussed today.

Keywords:

La problemática de la representación de la realidad histórica, política, social... y la indagación en el pasado a través de una narrativa de la memoria, recorre varias de las literaturas hispanoamericanas actuales desde los años ochenta y noventa, y parece haber comenzado también su andadura en el ámbito de la literatura infantil y juvenil; si bien, como indica Nofal, todavía queda mucho terreno por recorrer para poder hablar de la existencia de una «literatura de la memoria, pensada especialmente para chicos, dentro de las fronteras del género de la literatura infantil y capaz de circular en los ámbitos de la educación formal» (Nofal 21)1.

Sin embargo, podemos trazar ya un recorrido por diversos textos que abordan, desde diferentes perspectivas, episodios de una historia más o menos cercana y que, sin tratarse específicamente de narrativa histórica,

\section{María Bermúdez}

Profesora de la Universidad de Granada, Departamento de Didáctica de la Lengua y la Literatura. Investigadora especializada en literatura infantil y juvenil, narrativa hispanoamericana contemporánea y didáctica de la literatura.
1

La autora - centrándose en el ámbito argentino- cita el libro de Graciela Montes, El golpe, publicado en 1996 en Página/12 que luego formó parte del libro $E l$ golpe y los chicos (Buenos Aires, Colihue, 1996), como ejemplo de esa recuperación de la memoria en el marco del género testimonial o documental.

Una narrativa infantil y juvenil para la memoria

MARÍA BERMÚDEZ MARTÍNEZ 
Recupera, además, unas declaraciones de Rodari que sitúan el tema en su dimensión histórica y política: «La literatura infantil, en sus inicios, sierva de la pedagogía y de la didáctica, se dirigía al niño escolar - que ya es un niño artificial-, de uniforme mesurable según criterios meramente escolares basados en el rendimiento, en la conducta, en la capacidad de adecuarse a modelo escolar. Entre los siglos $\mathrm{XVII}$ y XVIII nacen las primeras escuelas populares, fruto último de las revoluciones democráticas y de la industrialización. Hacen falta libros para esas escuelas; libros para 'los hijos del pueblo'. Les enseñarán las virtudes indispensables para las clases subordinadas; la obediencia, la laboriosidad, la frugalidad, el ahorro. La literatura infantil es uno de los vehículos de la ideología de las clases dominantes».

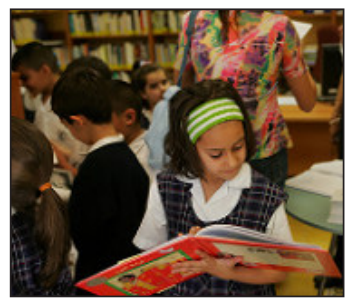

Anna Lindh Foundation.

Una narrativa infantil y juvenil para la memoria

MARÍA BERMÚDEZ MARTÍNEZ recuperan hechos significativos de la realidad histórica, política y social para dar cuenta, memoria, del pasado.

Este artículo se propone como un acercamiento, incompleto sin duda - no pretendemos ser exhaustivos ante un panorama tan amplio y complejo, sino simplemente abordar algunas interesantes lecturas que van trazando esa senda-, a esos acercamientos que la narrativa infantil y juvenil hispanoamericana ha tenido hacia la realidad histórica y social y el tratamiento de la memoria, atendiendo especialmente al panorama argentino y poniendo a la vez sobre la mesa algunas de las cuestiones centrales en las que se debate la literatura infantil y juvenil en la actualidad.

Literatura infantil y juvenil y educación: fuerzas de poder en el ámbito educativo y cultural

Las palabras de Nofal citadas anteriormente nos remiten, asimismo, a uno de los ejes que han ido conformando la literatura infantil y juvenil desde sus orígenes, fuera y dentro del ámbito hispanoamericano: su presencia en el ámbito educativo y el valor didáctico-pedagógico indisociablemente unido a una literatura específica para niños; un aspecto que enlaza directamente con la problemática de los valores en la literatura infantil y juvenil y el funcionamiento de las fuerzas de poder en el ámbito educativo y cultural.

Si bien la literatura infantil surge estrechamente unida a una finalidad didáctica, llega un momento en que se desvincula de esas ataduras y da rienda suelta a la fantasía en el marco de una libertad de miras que nunca antes había conquistado. No obstante, los últimos recorridos vuelven a poner sobre la mesa la tensa relación entre una literatura que se llama a sí misma y se piensa como literatura y sus aplicaciones didácticas en el ámbito educativo. Marcela Carranza, en el año 2006, se preguntaba:

¿Qué ha sucedido en el campo de los libros para chicos para que las editoriales insistan de este modo en el cruce entre moral y literatura? Algo está pasando en la sociedad, pero particularmente en la escuela, principal comprador de libros para chicos, para que las empresas editoriales apunten sus dardos a los valores, como una evidente estrategia de mercado. La moral y los libros reunidos como estrategia de marketing.
La autora recopila diferentes propuestas de diversos agentes internos y externos al campo de la literatura para niños (autores, editores, padres, maestros, bibliotecarios, investigadores especialistas en el campo o los medios de comunicación), que son portadores de ese discurso que hace «instalar el predominio de una función social-pedagógica-moral en la lectura de los textos destinados a las nuevas generaciones»; sobre el que, sin embargo -insiste-, hay mucho que discutir, planteando una serie de interrogantes que alcanzan a las esferas centrales de la diana:

¿Por qué hoy tiene tanta fuerza este discurso pedagógico-dogmático de transmisión de los valores a las nuevas generaciones? ¿Por qué la literatura y otras manifestaciones artísticas son elegidas como formas privilegiadas para esa transmisión? ¿Por qué la literatura infantil resulta tan permeable a este uso moral al que se la somete? ¿Qué concepción de niño supone este programa de transmisión de valores? ¿Qué concepción de la lectura, en particular de la lectura literaria, y del lector implica este uso moral de lo literario??

En el eje de la reflexión de Carranza está la situación actual de una literatura infantil que parece no haber superado esa etapa o que, más bien, por diversas razones, después de una liberación de las ataduras del didactismo y la moral, ha vuelto a ella, si bien desde posturas diferentes ya que - como apunta la autora recuperando a Ricardo Mariño (1999) - los contenidos moralizantes de antaño son ahora reemplazados por textos que despliegan una mirada más «progre» en su modo de entender la realidad: "contenidos más actuales, y por esta razón casi invisibles», que podríamos llamar "políticamente correctos», al tratarse de textos para ser tolerantes, no discriminar, fomentar el diálogo, respetar el medio ambiente, hablar de problemáticas sociales (drogadicciones, sida, pobreza, anorexia, maltrato infantil...). En definitiva, nos encontramos ante otra forma de tutelaje que contrasta radicalmente con la idea de texto literario abierto (a la libertad de interpretaciones, a la plurisignificación), generador de expectativas, propulsor de interrogantes más que contenedor de verdades absolutas que, como señala Carranza, acercan el texto que se propone inicialmente como literario a la «publicidad, la propaganda, el panfleto o el sermón». Se 
convierte así, también y de manera destacada, la literatura infantil y juvenil, en un factor de dominación cultural.

Es evidente que la literatura, como expresión cultural que es, nos enseña a vivir y nos transmite valores; pero entender que esa es la funcionalidad de los textos, que ese es el objetivo de su escritura y el fin de su lectura, es equivocar sin duda los términos, y eso es lo que parece propugnarse desde el discurso de los valores en la literatura tan extendido en la escuela y la sociedad. Esto es algo que en ningún modo se cuestionaría en la literatura adulta y que, sin embargo, parece totalmente permisible cuando hablamos de literatura para niños. Ese control sobre la escritura viene una vez más a tratar de «proteger» al lector de los supuestos peligros de la lectura literaria. De ahí que también, durante mucho tiempo, haya estado ausente de esta literatura para niños y jóvenes el tratamiento de determinados temas «peligrosos» en el marco de esa esfera de protección trenzada sobre el menor, de acuerdo con determinados principios pedagógicos o psicológicos de control: el dolor, la muerte, la crueldad y la maldad (pensemos en las distintas elaboraciones de los cuentos de hadas, en nuestra entrañable Caperucita escondida en un armario...), la utopía, la fantasía, el amor o el odio y, cómo no, determinados aspectos de la historia... Por ello la construcción de un mundo literario infantil dirigido a los «amiguitos» niños y poblado de animalitos a orillas de idílicos laguitos, bosquecitos y praderitas... que no hacen sino desplegar una determinada idea que el adulto tiene o desea desplegar sobre el menor escamoteando la realidad concreta del niño:

¿Qué es lo que se quiere proteger con ese gesto? Esconder lo malo, las brujas, los fantasmas, la muerte, son eternas discusiones en los ámbitos de selección del material infantil. Cómo nombrar lo feo, lo terrible, lo siniestro..., buscar un nombre que el sistema hegemónico de producción editorial para chicos se empeña en borrar. Faltan las palabras para expresar lo vivido, faltan las palabras en la ficción para inscribir las buellas dolorosas del pasado (Nofal; la cursiva es nuestra).

Significativa y esclarecedora es la imagen dibujada en el título del estudio de Graciela Montes El corral de la infancia que nos presenta - en palabras de Ana $\mathrm{M}^{\mathrm{a}}$ Machado- la infancia "como encerrada en un corral con el pretexto de ser protegida pero al mismo tiempo privada de libertad, atrapada en una prisión» (Machado 8):

[...] con el tiempo se elaboraron reglas muy claras acerca de cómo tenía que ser un cuento para niños. En pocas palabras, tenía que ser sencillo y absolutamente comprensible (había incluso una pauta que fijaba el porcentaje de vocabulario desconocido que se podía tolerar), tenía que estar dirigido claramente a cierta edad y responder a los intereses rigurosamente establecidos para ella. No podía incluir la crueldad ni la muerte ni la sensualidad ni la bistoria, porque pertenecian al mundo de los adultos y no al «mundo infantil», a la «dorada infancia», eran bestias del otro lado del corral y había que tenerlas a raya. Era común que esa literatura llamara a su pretendido interlocutor, al niño ideal, «amiguito»: una manera de ganarse su confianza y, a la vez, mantenerlo en su lugar (Montes 21; la cursiva es nuestra).

Crueldad, muerte, horror, sensualidad, historia y fantasía aparecen como fronteras infranqueables para una escritura dirigida a los niños que impone un singular y mal entendido tipo de realismo («la realidad era despojada de un plumazo de todo lo denso, matizado, tenso, dramático, contradictorio, absurdo, doloroso; de todo lo que podía hacer brotar dudas y cuestionamientos», Montes 22), aquel que no incomoda al adulto, que perfila su figura ideal de infancia y le sirve para ejercer el control sobre ella. Desde esos parámetros, está claro que «el ingreso de la realidad histórica al mundo infantil resulta siempre escandalosa» ${ }^{3}$ (Montes 23).

Habrá que esperar a bien entrado el siglo XX para que, con el desarrollo del psicoanálisis, la

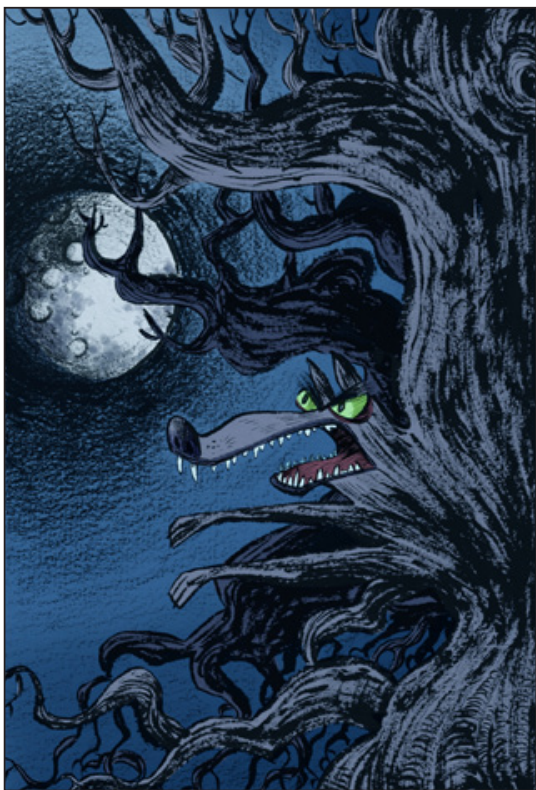

La historia interminable: creación de Gmork (Loren) http://recursostic.educacion.es/bancoimagenes/web/. fantasía entre de lleno en el mundo literario infantil, apoyada por la idea piagetiana del juego como constructor de lo real y elemento decisivo en el desarrollo de la inteligencia, si bien, como ya señalamos, aún muchos siguen protegiendo al niño de esos «peligros» encerrándolo en su «corral». La literatura para niños entra entonces en una etapa en que prima el valor literario del texSeñala Montes: «Cuando en 1986 edité una serie de libros de información para niños Entender y participar- en los que hablaba del terrorismo de Estado que se había instalado en mi país a partir de 1976; varios me reprocharon que les 'hablara de esas cosas a los chicos' y un periodista del diario La Nueva Provincia de Bahía Blanca Carlos Manuel Acuña, curiosa y coherentemente, incluyó en una misma nota condenatoria esas 'insoportables' referencias a asesinatos $y$ torturas en un libro para niños y 'la educación sexual en las escuelas'. Diez años después, en 1996, cuando publiqué El golpe y los chicos, un relato aún más pormenorizado y puntual del terrorismo de Estado siguió habiendo quienes me reprocharon que insistiera en recordarles 'esas cosas tan tristes' a niños» (23). 


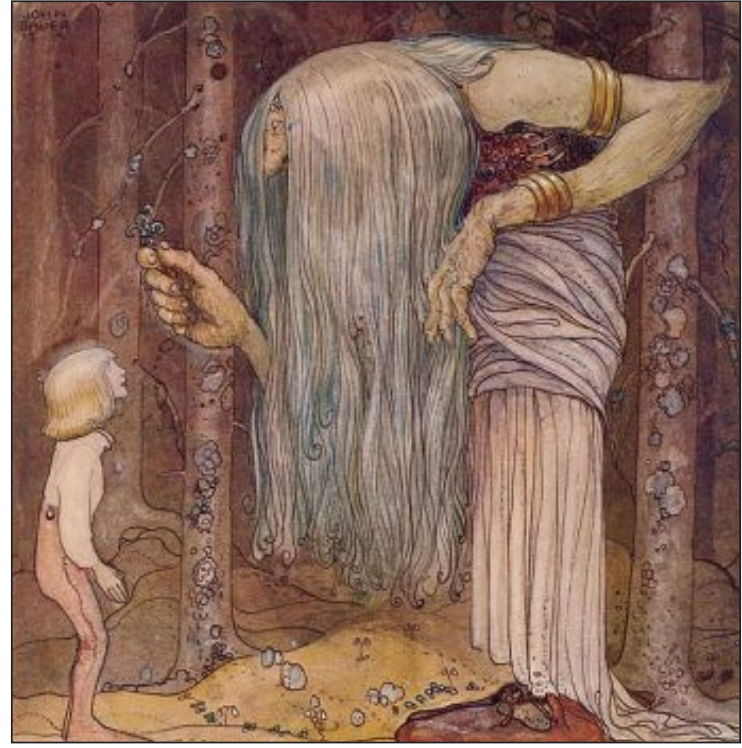

to y el desarrollo de finalidades lúdicas inherentes al juego literario por encima de todo condicionante didáctico, con un desarrollo de la fantasía y una presencia palpable de la realidad sin ataduras que, no obstante, como señala Montes, siempre acababan - aun cuando intentaban contenerlaspor zafarse y colarse en un mundo literario infantil que cada llustración de John Baver. vez se acerca más al mundo adulto borrando las fronteras y afirmando un único territorio, entre la fantasía y la realidad, para la literatura («Hoy hay señales claras de que el corral se tambalea, de que grandes y chicos se mezclan indefectiblemente», Montes 27).

\section{La Literatura infantil en la dictadura militar argentina}

Posturas de este tipo - de control sobre la escritura infantil y la idea de infancia- llevadas al límite, fueron aprovechadas y sirvieron de justificación, en su momento, para determinadas actitudes hacia los libros para niños y jóvenes, como las que refleja la censura sobre la literatura infantil y juvenil en varios países hispanoamericanos en el marco de las diferentes dictaduras que recorrieron su historia en el pasado siglo. Nos centraremos en analizar, especialmente, el caso de la última dictadura militar argentina, el eufemísticamente llamado «Proceso de Reorganización Nacional» que sufrió el país entre 1976 y 1983. El amplio alcance de la censura en el marco de una dictadura afectó también a la literatura y, de manera muy especial, como señala la periodista Judith Gociol en el fascículo Un golpe a los libros (1976-1983), a la literatura infantil y juvenil:

Si bien las prohibiciones se instalaron en todos los frentes, hubo un espacio que el ojo del censor vigiló con firmeza: el de la literatura infantil. Los militares se sentían en la obligación moral de preservar a la niñez de aquellos libros que - a su entender- ponían en cuestión valores sagrados como la familia, la religión o la patria. Gran parte de ese control era ejercido a través de la escuela, tal como demuestran las instrucciones de la 'Operación Claridad' (firmadas por el jefe del Estado Mayor del Ejército, Roberto Viola), ideadas para detectar y secuestrar bibliografía marxista e identificar a los docentes que aconsejaban libros subversivos (citado por Sotelo).

Se desarrolla así una política de «genocidio cultural» que afecta de manera directa a la literatura infantil y juvenil, en muchos casos con prohibiciones directas y totales de libros, cierre de editoriales, quema de libros o, en otros, con censuras parciales que si bien no prohibían la circulación de los textos sí exigían su modificación, reelaboración o recortes para su circulación. Más allá de la irracionalidad de cualquier pensamiento único y autoritario como el que subyace en la base de cualquier dictadura, uno de los factores motivadores de esta censura directa sobre la literatura para niños tiene que ver con la posibilidad que la ficción ofrece para abrirse a nuevos mundos, a diferentes realidades y a diversas formas de entender la vida y la realidad. Y así aparece, evidente, en muchas de las argumentaciones de tales prohibiciones, si bien enmascaradas en otro tipo de justificaciones más específicas o puntuales. Tengamos en cuenta, además, que la literatura - como apunta Josefina Oliva respondiendo a la pregunta "¿Qué les podía molestar a los militares de un cuento para chicos?»-, «forma parte de la producción cultural de una época» y los años setenta «marcaron un periodo de lucha y resistencia que se dejaba ver en las creaciones de carácter cultural y que se oponían al discurso del poder de la dictadura» (Raggio y Oliva 2). Si bien se trata de textos que no tematizan directamente la dura situación vivida, sí nos ofrecen - como en el caso de la literatura dirigida a adultos - vías de crítica a una realidad uniforme, monolítica y direccional que es la que trataban de imponer los militares y civiles que en aquel momento ostentaban el Poder.

A su vez, otra de las causas tiene que ver directamente con la transformación que estaba sufriendo la literatura misma ya que durante los años setenta se producen en la esfera de la producción para niños y jóvenes «cambios que darían un vuelco en la literatura infantil, depositados en el lenguaje, en la transformación de las atmósferas en las cuales transcurren las historias, en una nueva relación con el 
lector y en el humor y la parodia como forma de criticidad» (Raggio y Oliva 2); dibujando líneas paralelas a la literatura adulta que suponen, en el marco de la literatura para niños el triunfo definitivo de la fantasía y la apertura de significados, algo que evidentemente no gustaba a los por entonces gestores del país:

La fantasía, los finales abiertos, las preguntas, el color, las líneas de los dibujos que se salían de una figura «real», eran capaces de abrir nuevos interrogantes en los chicos, y esto no convenció a los dictadores de turno. Justamente lo que menos vieron en las nuevas obras fue literatura. A través de cada historia se suponía un arma sospechosa, difusora de ideas peligrosas, que atentaban contra los valores de «la moral, la familia y la patria» que se pretendían imponer (Raggio y Oliva 2).

Ya la escritura de $\mathrm{M}^{\mathrm{a}}$ Elena Walsh anticipaba, desde los años sesenta, esa primacía de la imaginación, la invención y el elemento lúdico y humorístico, con una literatura dirigida a los niños en la que el objetivo fundamental y razón de ser de la misma es el placer por la lectura en sí misma y no el elemento didáctico-moralizante que la había teñido hasta entonces. Después nos encontramos con las escrituras de Laura Devetach, Elsa Bornemann, Gustavo Roldán, Graciela Cabal o Graciela Montes, entre otros. Esta última explica así el cambio producido desde una literatura entendida como forma de aprendizaje y tutela sobre el niño a una literatura gestada como literatura misma y desde la tradición literaria misma:

En general veníamos de la literatura, es decir que éramos lectores, y, cuando escribíamos, teníamos ilusiones de literatura y no de escuela. Hacíamos entrar en el imaginario otro tipo de historias. Nos negábamos a las moralejas, nos gustaba urticar. No éramos solemnes, recurríamos al humor. Y usábamos otro tipo de lenguaje. Un lenguaje cercano, menos neutro y más propio, más vital. Como éramos lectores de literatura, solía haber intertextos, un cierto diálogo con la literatura argentina y mundial que nos precedía; ese vínculo con la literatura adulta resultaba bastante novedoso... (Machado y Montes).

La censura sobre los libros estaba a cargo de la Dirección General de Publicaciones, que ejercía el control político. Solía partir bien por iniciativa propia de la Dirección o bien por denuncias de organismos oficiales o de personas particulares. A partir de ahí se realizaba un análisis ideológico-político del libro y se emitía un informe (Invernizzi y Gociol 66). La Comisión Orientadora de Medios Educativos (desde 1979) y la Superintendencia Nacional de Enseñanza Privada (SNEP), fueron los medios encargados de ejercer ese control sobre la literatura para niños y jóvenes. Evidentemente, los libros escolares e infantiles fueron un foco de especial atención, ya que la escuela era uno de los ejes fundamentales para ejercer el control y difundir el mensaje. El Ministerio de Educación y Cultura obligó a la difusión en los centros escolares del opúsculo Subversión en el ámbito educativo (conozcamos a nuestros enemigos), que tuvo una amplia vigencia durante los años 1977, 1978 y siguientes. Entre otras cuestiones, indicaba (Capítulo III «Estrategia particular de la subversión en el ámbito educativo»; apartado dedicado al nivel inicial - preescolar y primario-):

El accionar subversivo se desarrolla a través de maestros ideológicamente captados que inciden sobre las mentes de los pequeños alumnos, fomentando el desarrollo de ideas o conductas rebeldes, aptas para la acción que se desarrollará en niveles superiores.

La comunicación se realiza en forma directa, a través de charlas informales y mediante la lectura y comentario de cuentos tendenciosos editados para tal fin. En este sentido se ha advertido en los últimos tiempos, una notoria ofensiva marxista en el área de la literatura infantil. En ella se propone emitir un tipo de mensaje que parta del niño y que le permita «autoeducarse» sobre la base de la «libertad y la alternativa»(Invernizzi y Gociol 105).

Las indicaciones de la «Operación Claridad», dirigida por el jefe del Estado Mayor del Ejército del Proceso, Roberto Viola, incidían sobre el control de los siguientes aspectos:

1) Título del texto y la editorial, 2) Materia y curso en el cual se lo utiliza, 3) Establecimiento educativo en el que se lo detectó, 4) Docente que lo impuso o aconsejó, 5) De ser posible se agregará un ejemplar del texto. Caso contrario, fotocopias de algunas páginas, en las que se evidencie su carácter subversivo, 6) Cantidad aproximada de alumnos que lo emplean, 7) Todo otro aspecto que se considere de interés (Gociol).

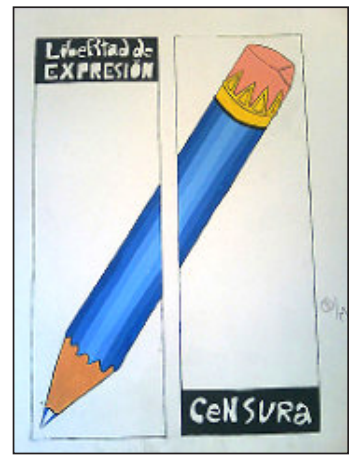

Julián Ortega Martínez. "Libertad de expresión/Censura".
Una narrativa infantil y juvenil para la memoria

MARÍA BERMÚDEZ MARTÍNEZ 
Como el caso de La cuba elec trolítica, libro de Física censurado porque contenía la palabra «cuba» en su título; o El cubismo. Invernizzi y Gociol (14) señalan también la prohibición de "la matemática moderna por su alusión a las clases, los conjuntos y los vectores». para la memoria

MARÍA BERMÚDEZ MARTÍNEZ
En el panorama general de la edición argentina, editoriales tan destacadas como Eudeba (Editorial Universitaria de Buenos Aires) y CEAL (Centro Editor de América Latina) fueron perseguidas. Significativa fue la quema de libros del depósito del CEAL en un baldío de Sarandí, donde ardieron un millón y medio de ejemplares. Muchos escritores, cuyos libros fueron censurados, se exiliaron; otros fueron encarcelados, torturados y otros engrosan la lista de 30.000 desaparecidos.

Aunque en algunos casos los informes recuperados parecen responder a «la ignorancia, capricho o paranoia de los censores militares» y en otros parece que bastaba con que aparecieran términos como "pueblo», «huelga» o determinadas temáticas solidarias ${ }^{4}$, para que fuesen prohibidos; en la mayor parte de los casos, como indica Invernizzi, los informes eran precisos, estaban debidamente motivados y basados en una investigación:

El funcionamiento de la censura era extremadamente simple, eficiente y prolijo. El criterio era: no se censura porque sí; porque fulano cae mal o porque es zurdo, porque es comunista o peronista combativo. Detrás de todo acto de censura de libros había una investigación del libro. Muchas de esas investigaciones las encontramos. A veces el informe sobre el libro son tres carillas, y a veces hasta cuarenta. Esos informes eran escritos por intelectuales, por profesionales, profesores de letras, abogados, sociólogos, antropólogos. Gente inteligente, capaz y preparada. Y más de uno de estos estudios los sorprendería porque es más que aceptable el nivel intelectual. Es más: en líneas generales, deberíamos decir que tenían razón en lo que decían, no se equivocaban. Desde el punto de vista de los intereses de clase de la dictadura y de su proyecto ideológico, los libros que ellos identificaban como «peligrosos» o como representantes del pensamiento crítico, por decirlo de alguna manera, estaban correctamente identificados, no se equivocaban (citado por Ruffa).

A la par de esta labor de censura, había también un proyecto complementario de rellenar ese hueco cultural, un "plan de sustitución cultural», de reemplazar ese vacío censurado con producciones orientadas hacia su proyecto de sociedad basada en la premisa «estado, religión y familia» (Invernizzi y Gociol 114).

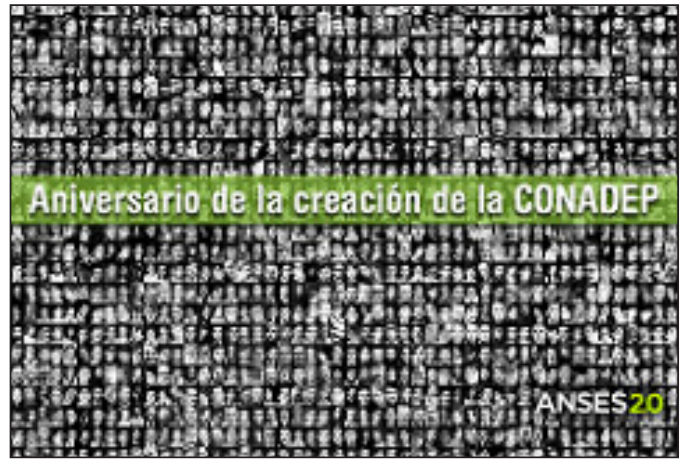

15 de diciembre. Aniversario de la creación de la CONADEP.

Un elefante ocupa mucho espacio, de Elsa Bornemann

El 13 de octubre de 1977 el libro Un elefante ocupa mucho espacio, de la argentina Elsa Bornemann fue prohibido por el Decreto $n^{\circ}$ 3155/77 del Poder Ejecutivo Nacional. El informe sobre el libro, recogido en el Decreto 1774/73 (Raggio 13), indica que "propicia la difusión de ideologías, doctrinas o sistemas políticos, económicos o sociales tendientes a derogar los principios sustentados por nuestra Constitución Nacional», incidiendo en el análisis de algunos de los cuentos que integran el volumen.

Con respecto al cuento homónimo al volumen, «Un elefante ocupa mucho espacio», el informe señala que en el mismo «se evidencia la intencionalidad de la autora, a través de una forma cooperante de disgregación social, tratando de sembrar ideas disolventes en la mente infantil». El cuento narra la historia de un elefante que decide convocar a todos los animales de su circo a una huelga general, en busca de la «alegría de la libertad». Consigue el apoyo del resto de animales, que le nombran «delegado», lanzándose a la tarea de trastocar el orden determinado adiestrando ahora ellos, los animales, a quienes antes les adiestraban, los hombres ( ${ }_{i}$ Caminen en cuatro patas y luego salten a través de estos aros de fuego! ¡Mantengan el equilibrio apoyados sobre sus cabezas! ¡No usen las manos para comer! ¿Rebuznen! ¡Maúllen! ¡Píen! ¡Ladren! ¡Rujan!», Bornemann 13). El dueño del circo no puede resistir la situación y accede al trato, embarcando a todos los animales de vuelta a África, a la Libertad, contratando dos aviones «porque todos sabemos que un elefante ocupa mucho, mucho espacio...» (14). 
«Caso Gaspar», el segundo de los relatos que integran el volumen, nos presenta a un personaje que, cansado de gastar suelas recorriendo la ciudad vendiendo manteles, decide un día empezar a caminar sobre sus manos. La actitud de los demás hace que Gaspar se sienta rechazado («Me rechazan porque soy el primero que se atreve a cambiar la costumbre de marchar sobre las piernas... Si supieran qué distinto se ve el mundo de esta manera, me imitarían...» 20); le tildan de «loco», pero nada afecta a un Gaspar que entiende las críticas como «opiniones» que incluso le divierten, haciendo caso omiso de ellas. Un día es detenido por la Policía («Un camión celular lo condujo a la comisaría más próxima, $\mathrm{y}$ allí fue interrogado por innumerables policías» que lo consideran por su forma de andar «muy sospechoso", 21-22); pero Gaspar logra revertir la situación ya que hace ver a la Policía que caminar sobre las manos no forma parte del entramado de prohibiciones ( $¿ \mathrm{E} E$ TÁ PROHIBIDO CAMINAR SOBRE LAS MANOS? Y por más que buscaron en pilas de libros durante varias horas, esa prohibición no apareció. No, señor. ¡No existía ninguna ley que prohibiera marchar sobre las manos ni tampoco que obligara a usar exclusivamente los pies» 22). De esa manera «Gaspar recobró la libertad de hacer lo que se le antojara, siempre que no molestar a los demás con su conducta» (23). El decreto incide en que en este relato "existe por parte de la autora la intencionalidad de crear en la mente infantil imágenes distorsionadas de nuestro sistema de vida, utilizando para ello la forma del trabajador que intenta un cambio en las formas y que por ello es reprimido».

Las referencias a la realidad política y social vuelven a estar presentes en una escritura que hace de la imaginación el eje sobre el que se construye la narración a través de trabajo poético con el lenguaje, como en «Pablo», que narra la historia de un pueblo marinero que se queda sin voz, en el que las palabras vuelan hasta detenerse ante la casa de Pablo «el poeta, hermano del amor y la madera, amigo de paraguas y flores, caminador de muelles y de inviernos, timonel del velero de los pobres, voz de los tristes, de piedras y olvidados...», que acababa de morir. Las palabras rinden su último homenaje al poeta «su ángel guardián, su domador, su padre, su sembrador» (36). El informe señala que el relato «está dedicado a Pablo Neruda, a quien se apologiza y con un lenguaje claro y accesible a los niños se les acerca al poeta chileno activo militante comunista».

«Donde se cuentan las fechorías del Comesol», nos presenta a un gato abandonado, «pequeño tigre de ciudad», aislado del resto de gatos absorto en la idea de construir un aparato, un «acaparasol» para atraer los rayos solares. Construye su invento y deja sin sol el baldío en el que viven, de manera que el resto de animales debe com-

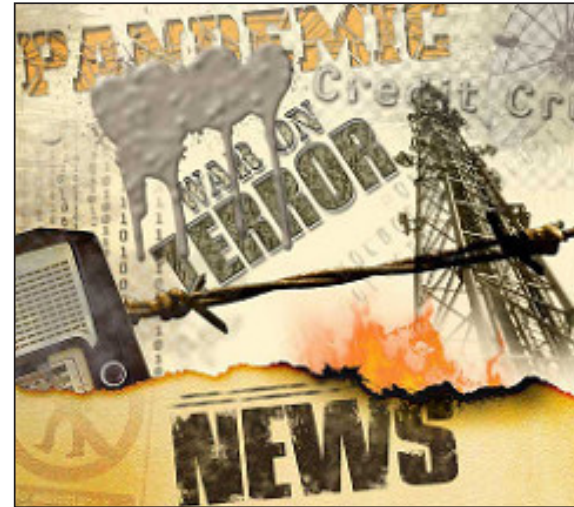

"Sub-version 2.0". prarle barriles con rayos de sol para poder sobrevivir. La situación llega a ser tan extrema que los gatos se unen en «asamblea general» $\mathrm{y}$ juntos consiguen destruir el acaparasol: «Nunca había imaginado que todos los demás podían unirse en su contra. Juntos, juntos. Y juntos abrieron los toneles de sol que se apilaban formando casi una montaña. Y juntos destrozaron el acaparasol» (89). Así, la interpretación que la censura realiza del cuento es que «el tigre representa al sistema capitalista que oprime a los gatos, la clase trabajadora, situación que se mantiene hasta que los gatos unidos en defensa de sus intereses destruyen al Comesol [...] En síntesis, aquí se muestra la lucha del proletariado con conciencia de clase contra el capitalismo al cual derrota».

En definitiva, se considera que los relatos de Un elefante ocupa mucho espacio "poseen una finalidad de adoctrinamiento que resulta preparatoria a la tarea de captación ideológica del acciona subversivo», de manera que «dado el contenido ideológico existente en la publicación, lesivo hacia nuestro sistema de vida occidental y cristiano y teniendo en cuenta fundamentalmente que la obra se dirige al público infantil, se propone la apreciación referida y su inclusión en lo dispuesto por la ley 20.840/74» (recogido en Raggio 12). Así, el decreto de prohibición (3155/77), ordena el inmediato secuestro de todos los ejemplares en circulación del libro, al considerar que, en virtud de «que uno de los objetivos básicos fijado por la Junta Militar en el acta del 24 de marzo de 1976 es el de restablecer la vigencia de los valores de la moral cristiana, de la tradición nacional y de la dignidad del ser argentino» y de que «dichos objetivos se complementan con la plena vigencia de la institución familiar y de un orden social que sirva efectivamente a los objetivos de la
Una narrativa infantil y juvenil para la memoria

$\overline{\text { MARÍA BERMÚDEZ MARTÍNEZ }}$ 
Nación», el libro de Bornemann (así como El nacimiento, los niños y el amor, de la autora francés Agnes Rosenstiehl, ambas publicaciones de Ediciones Librerías Fausto), «agravia a la moral, a la familia, al ser humano y a la sociedad que éste compone». Se señala también a la editorial, que «comparte dichos agravios y es contumaz en esa difusión». Así, se decreta la prohibición y el cese temporal de la actividad de la editorial:

Art. 1. Prohíbese la distribución, venta y circulación en todo el territorio nacional, de los libros «Un elefante ocupa mucho espacio» de Elsa Isabel Bornemann y «El nacimiento, los niños y el amor» de Agnés Rosentiehl, ambos de "Ediciones Librería Fausto» y secuéstrense los ejemplares correspondientes.

Art. 2. Dispónese la clausura por el término de diez días de "Ediciones Librería Fausto» con domicilio en Santa Fe 1715, Capital Federal.

Art. 3. Lo dispuesto en el artículo anterior no impedirá la realización de las tareas administrativas, inherente a «Ediciones Librería Fausto».

Art. 4. La Policía Federal dará inmediato cumplimiento a lo dispuesto en el presente decreto.

Art. 5. Comuníquese, etc. Videla - Harquindeguy. (Recogido en Raggio 13).

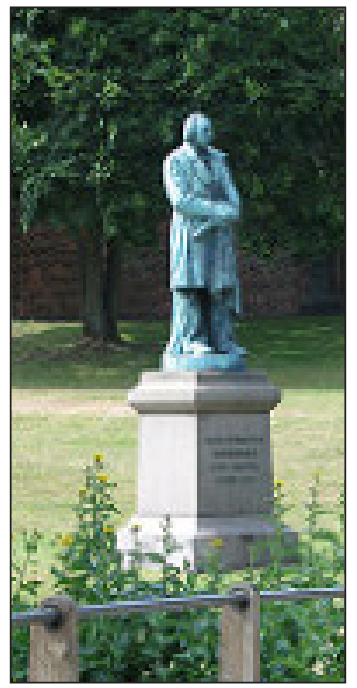

H.C. Andersen. Foto: Greger Ravik.
El alcance de esta prohibición motivó que Elsa Bornemann tuviera prohibido el acceso a cualquier centro de educación pública del país hasta el final de la dictadura (Invernizzi y Gociol 110), aún cuando un año antes $U n$ elefante ocupa mucho espacio había sido galardonado por el IBBY (International Board on Books for Young People) integrando el Cuadro de Honor del Premio Internacional «Hans Christian Andersen», que lo considera «un ejemplo sobresaliente de Literatura con importancia internacional». El libro no volverá a ser publicado hasta 1984, con el retorno de la democracia. Desde entonces se han realizado ya varias ediciones y su lectura actual, dentro y fuera del marco escolar, primando el valor estético de los relatos y el triunfo de la fantasía que representan en el marco de la literatura infantil y juvenil contemporánea, se propone sin duda como un importante ejercicio para la memoria de las generaciones actuales.

\section{La torre de cubos, de Laura Devetach}

La Torre de cubos se publicó por vez primera en 1966, por EUDECOR, la Editorial
Universitaria de Córdoba. El libro se editó con un estímulo del Fondo Nacional de las Artes. La autora ya había recibido previamente varias distinciones en concursos literarios por algunos de los relatos que lo integran y la obra tuvo muy buenas críticas en periódicos provinciales y nacionales (Clarín, El Diario de Mendoza y La Prensa, entre otros). Fue, sin embargo, prohibido, entre otras razones, "por su ilimitada fantasía». La prohibición se inició en la provincia de Santa Fe en 1976, de donde procede la autora, después continuó en Mendoza, Buenos Aires, la zona sur y finalmente, en 1979, se extendió a nivel nacional. La autora explica así el mecanismo de la censura:

Era la gente de adentro la que se encargaba de mandar lista... y el señor de charreteras en el escritorio firmaba... listo. Es más, los fundamentos, por ejemplo de la prohibición de La torre de cubos, yo sé quienes los dieron. Y son dos colegas» ( Raggio 3)

Sin embargo, Devetach indica asimismo que también fueron colegas y compañeros, educadores, maestros, los que propiciaron que dicha prohibición fuera subvertida y su libro siguiera circulando, oculto, escondido, sin nombre de autora, entre niños y jóvenes... (Invernizzi y Gociol 315). El maestro Paulino Guarido expone su testimonio («Bartolo ¡está vivito y coleando!») en la «Propuesta Didáctica. Libros: memoria con futuro», elaborada por Claudia Rodríguez Paoletti:

Bueno, lo cierto es que yo me había enamorado de dos cuentos: «La planta de Bartolo» de Laura Devetach y «Un elefante ocupa mucho espacio» de Elsa Bornemann. Un día comenzó a correr de boca en boca, en las escuelas, en el sindicato y en algunas librerías, que había una lista de libros prohibidos. Después, con el tiempo, nos enteramos que la lista estaba escrita, que amenazaban a los autores, que se quemaban los libros. Sin embargo, mientras tanto, yo quería que mis pibes disfrutaran de esta literatura; que conocieran a Bartolo, ese pibe tan pero tan solidario.

Entonces, para no meterme en problemas, lo que hacía era escribir en un cuaderno - en el cual los maestros teníamos que escribir lo que íbamos a enseñar día por día- nombres de otros cuentos, o cambiarle el autor o modificar el título. Había que tratar, además, que no quedara nada escrito, ni siquiera dibujos. Los que lo hacíamos - porque con el tiempo también nos enteramos que muchos compañeros hacían cosas 
parecidas - era intentar que eso quedara en la memoria y en el corazón de nuestros pibes. Fue la forma que muchos encontramos para no traicionar nuestros ideales y, a la vez, cuidarnos entre todos ${ }^{5}$.

Devetach pone de relieve el control sobre toda escritura que marcara modelos y mecanismos de convivencia o que reflejara aspectos relativos a la realidad social - como hemos visto en el caso de Un elefante ocupa mucho espacio-, así como el control ejercido sobre el lenguaje del que debía ser desterrada cualquier marca de regionalismo o coloquialismo; y recuerda el alcance que para ella, como escritora y como persona, tuvo la prohibición:

La torre de cubos se prohibió primero en la provincia de Santa Fe, después siguió la provincia de Buenos Aires, Mendoza y la zona del Sur, hasta que se hizo decreto nacional. A partir de ahí la pasé bastante mal. Porque no se trataba de una cuestión de prestigio académico o de que el libro estuviera o no en las librerías. Uno tenía un Falcon verde en la puerta. Yo vivía en Córdoba y más de una vez tuve que dormir afuera. Finalmente nos vinimos con mi marido a Buenos Aires en busca de trabajo y anonimato. Durante todo ese período quise publicar y no pude (Devetach).

Los pilares que sustentan la resolución $\mathrm{N}^{\circ} 480$ que prohibió a nivel nacional La torre de cubos, con fecha del 23 de mayo 1979 - que reitera los términos del Boletín $\mathrm{n}^{\circ}$ 142, de julio de 1979, por el cual el Ministro de Educación de la Provincia de Santa Fe prohibió el uso de La torre de cubos en las escuelas de educación primaria (recogida en Nofal, «Los domicilios de la memoria»)son su «simbología confusa, cuestionamientos ideológico-sociales, objetivos no adecuados al hecho estético, ilimitada fantasía y carencia de estímulos espirituales y trascendentales», señalando, de manera más específica

Que algunos de los cuentos narraciones incluidos en el libro, atentan directamente al hecho formativo que debe presidir todo intento de comunicación, centrando su temática en los aspectos sociales como la crítica a la organización del trabajo, a la propiedad privada y al principio de autoridad enfrentando grupos sociales, raciales o económicos con base completamente materialista, como también cuestionando la vida familiar, distorsiones y giros de mal gusto, lo cual en vez de ayudar a construir, lleva a la destrucción de los valores tradicionales de nuestra cultura (Invernizzi y Gociol 313).
Muchos de los elementos de juicio coinciden con los términos de la prohibición de $U n$ elefante ocupa mucho espacio, pero en el caso del libro de Devetach destaca la formulación explícita como criterio específico de censura su «ilimitada fantasía». La escritora Graciela Montes, reflexiona sobre esta construcción utilizada por los represores en la resolución ministerial:

En fin, la fantasía es peligrosa, la fantasía está bajo sospecha: en eso parecen coincidir todos. Y podríamos agregar: la fantasía es peligrosa porque está fuera de control, nunca se sabe bien adónde lleva.

Pero ¿de qué se acusa en realidad a la literatura infantil cuando se la acusa de fantasía?; ¿por qué tanta pasión en la condena?; ¿en nombre de qué valores se lanza el ataque?; ¿qué es lo que se quiere proteger con ese gesto? Tengo la impresión de que, en esta aparente oposición entre realidad y fantasía, se esconden ciertos mecanismos ideológicos de revelación/ocultamiento que les sirven a los adultos para domesticar $y$ someter (para colonizar) a los niños (Montes 16).

Laura Devetach señala el giro que venía dando la narrativa para niños $y$ jóvenes en esos años como una de las causas de la censura a su libro, el paso de «valores de óptica adulta, estereotipados y previsibles» a la irrupción de "voces distintas» que introducían aspectos, temáticas, experiencias y voces «que no entraban en el listado oficial de lo aceptado para decir a los niños»; de manera que, «una vez más en el mundo»-quizás como si la memoria tampoco en ese momento funcionara - «lo diferente» se convirtió, del nuevo, en «lo prohibido o peligroso». La libertad creadora, y de su mano esa ilimitada fantasía, era una vez más escamoteada en defensa de una supuesta y nada inocente defensa de valores. La incomodidad del cuestionamiento de determinadas ideas y valores sociales y la fuerza arrolladora de la peligrosa fantasía fueron las causas de la prohibición; si bien las razones esgrimidas, como también en otros casos, se presentan como mucho más directas, visibles e incluso surrealistas: Recogido también en Gociol Véase asimismo el documental producido por Hernán Belón bajo la dirección de Nicolás Carreras, titulado «Prohibido no leer», realizado por la TV Pública y la Secretaría de Cultura de la Presidencia de la Nación, a través del Centro de Producción e Investigación Audiovisual en el marco del ciclo de documentales «30 Años de Democracia» (disponible en www.youtube.com/ watch? $v=y h S n l O O y b e w)$.

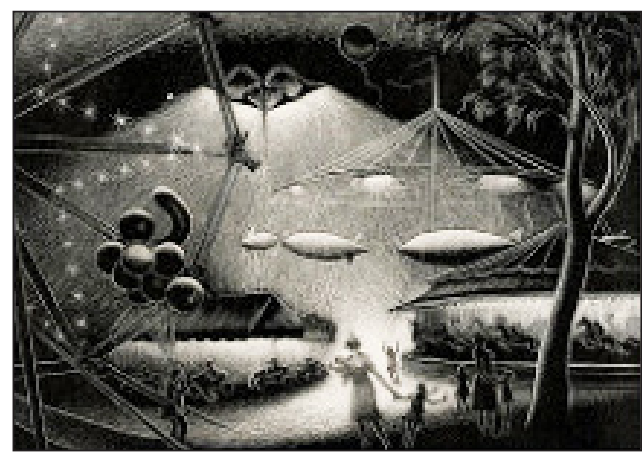

"Children's Carnival", Paul Landacre.
Una narrativa infantil y juvenil para la memoria

MARÍA BERMÚDEZ MARTÍNEZ 
"Me consta que, en mi caso, inquietaron de entrada ideas como la de la mujer gris que va lagañosamente a la iglesia todas las mañanas, en «El monigote de carbón». O el hecho de expresa que una niña roza con el vértice de las piernas la torre que armó con cubos, para saltar por sobre ella, en el cuento "La torre de cubos». O la descripción de la realidad de otra niña que duerme en la cocina y hace tareas en su casa mientras los padres salen a trabajar en «El pueblo dibujado». Eran ideas incómodas para los medios educativos y la iglesia. Sin embargo no eran esos los argumentos que luego se esgrimirían para la prohibición. La doble moral de siempre impulsó las argumentaciones por caminos más generales y casi surrealistas» (Devetach)

Una narrativa infantil y juvenil para la memoria

MARÍA BERMÚDEZ MARTÍNEZ
La doble moral de siempre impulsó las argumentaciones por caminos más generales y casi surrealistas. Les fue útil «La planta de Bartolo» y su conflicto ancestral entre los que tienen y los que no tienen. Es quizás lo más visible, pero no fue el único detonante de una prohibición que venía pautada de antes por mentes «civiles» que trabajaban en educación y en cultura, que denunciaron y construyeron los argumentos para el decreto final, de orden nacional (Devetach) ${ }^{6}$.

Invernizzi y Gociol (311) resaltan el valor de una censura que acusa, sorprendentemente salvo que en el marco de un decreto de prohibición, a la escritura de Devetach de «ilimitada fantasía», esa que recorre página a página toda La torre de cubos, desplegando un mundo de imaginación y valores poéticos destacables todavía hoy en el panorama de la literatura infantil. Es, sin duda, un texto que proclama la defensa de la literatura y la imaginación en el universo infantil a través de ocho relatos de enorme calidad estética. En el homónimo al volumen, «La torre de cubos", Irene construye una torre de cubos de colores e ingresa en el mundo fantástico de los caperuzos, cuyas casitas «eran pepitas de luz suspendidas entre las colinas» (Devetach, La torre de cubos 18), un universo de armonía ética y estética en el que sus habitantes defienden al que lo necesita, en el que no existen diferencias ni discriminaciones y que la autora describe envuelto en una atmósfera poética magistralmente dibujada ( $\mathrm{El}$ sol era un jugo lento sobre las colinas azules; Irene pasó toda la tarde conociendo maravillas. Aprendió a hacer delicadas torres de arena, a llamar a los peces rojos, a remontar barriletes desde los barquitos pardos», 17). La imaginación se despliega en «La planta de Bartolo» haciendo crecer cuadernos en la maceta en la que un día Bartolo sembró un precioso cuaderno. Bartolo destina esos cuaderno a los chicos pobres del pueblo que no pueden comprarlos y no se desprenderá de la planta ni por un «tren lleno de chocolate», ni por «una bicicleta de oro y doscientos arbolitos de navidad», ni por «un circo con seis payasos una plaza llena de hamacas y toboganes», ni por «una ciudad llena de caramelos con la luna de naranja»... Ni los soldaditos azules de la policía, enviados por el Vendedor de cuadernos, lo consiguen.

Un magnífico despliegue de imaginación y poeticidad inunda asimismo las páginas de «El deshollinador que no tenía trabajo», des- plegando la visión de una sociedad alienada en la que nadie toma conciencia de las necesidades del otro, salvo la mirada del niño Totó. Buenos Aires aparece como «una ciudad muy grande que no está hecha ni de caramelo, ni de galleta, ni de café, sino de casas altísimas, de autos, de semáforos y de calles que se trenzan entre sí nada más que para confundir al que no conoce la ciudad» (28). El niño Totó y Carbonilla, el deshollinador que le descubre las chimeneas en las que se esconden «las mejores canciones de viento, las adivinanzas y los versitos que a veces se escapan», viajan por la ciudad en busca del obelisco (que «se levantaba como un largo caramelo apuntando a las nubes», 37-38), montados en la bicicleta de Carbonilla, invisibles para el resto de habitantes que «estaban muy ocupados en pelear y con un enojo de muchos años encima» (37). Totó lleva a Carbonilla a casa de Laura, la «inventora de cuentos para chichos», que, en un ejercicio intertextual que recorre varios de los relatos del volumen, conoce «todas las chimeneas [...] y los deshollinadores y los monigotes de las paredes» y sabe «lo que les pasa a los chichos cuando se tragan un silbido» $\mathrm{y}$ "adonde se esconden las campanadas de los relojes». Será Laura quien consiga un trabajo para Carbonilla haciéndolo personaje del cuento.

Poeticidad, humor, irrupción de lo maravilloso, un amplio y magistral despliegue de imaginación sobre una escritura cargada de humanidad... son las marcas que caracterizan, asimismo, al resto de los relatos: «Nochero» (donde un viejecito recorta de la noche, con unas tijeras, una silueta de caballo que cobra vida para que Luis salga a cabalgar); "Mauricio y su silbido» y «Monigote de carbón» (en el que un monigote dibujado sobre una pared que ve pasar diariamente a la gente sin que nadie se fije en él - entre ellos a «la mujer gris que iba lagañosamente a la iglesia todas las mañanas» (69-70) - consigue desprenderse para que Roque lo complete dibujándole un «ojito negro, pícaro, redondito, un gran sombrero, un trabuco, botas, un velero maravilloso», pintándolo «con los colores más hermosos: con sol, con naranjada, con briznas de pasto y caramelos de frutilla» para que desde entonces luzca orgulloso, premiado, enmarcado en la pared, 76-77); «El pueblo dibujado» por Laurita (un pueblo con lluvia y sin colores cuyos monigotes cobran vida y aprenden a hablar con sopa de letras); 
y «Bumble y los marineros de papel» que descubren el mar y dibujan su silueta muy cerca de la orilla. Los relatos de Devetach, envueltos en una atmósfera general de fantasía e irrealidad, nos muestran además, a través de pequeñas pinceladas, huellas o atmósferas que se despliegan por ese universo poético (los soldaditos azules de la policía enviados por el Vendedor de cuadernos para destruir a Bartolo; los habitantes de Buenos Aires que nos muestra «El deshollinador que no tenía trabajo» como seres «muy ocupados en pelear y con un enojo de muchos años encima»...), rastros de una realidad exterior inabordable e inexplicable. En este sentido, la escritora apunta al trabajo con el lenguaje realizado por los escritores argentinos durante el período:

[...] muchos argentinos, habíamos aprendido a hablar de alguna manera en doble sentido, donde acá podía andar perfectamente pero en otro lado se podían leer un montón de cosas que no estaban tan manifiestas. Ella me decía que habíamos hecho una especie de trabajo en el lenguaje y debe haber sido así. Es decir, así como uno hizo un trabajo con su propio tono, con su propio cuerpo, con su vida, supongo que aprendió a trabajar elípticamente y sin embargo diciendo cosas, ¿̨no?» (Raggio 4).

Unas veces por la necesidad de escamotear esa censura que, sin embargo, como venimos observando, fue pertinaz en el campo de la literatura para niños y jóvenes; otras por la necesidad de nombrar el horror desde posicionamientos que permitan hablar cuando no se puede narrar o cuando, tras el horror, ya no quedan palabras; la literatura argentina del período, como indicaba Devetach, habla en un doble sentido, crea un lenguaje y un tono propio que permite hablar sin hablar. Ese es el caso, por ejemplo, haciendo una correlación con la literatura para adultos, de Nadie nada nunca, de Juan José Saer o Respiración artificial de Ricardo Piglia (ambas publicadas en 1980), narraciones que se convierten en la primera figuración de la violencia de la argentina de los años ochenta y noventa y en las que, desde diferentes posiciones, lo real histórico, político, entra en la literatura a través de estrategias narrativas muy elaboradas y basadas en una figuración alegórica de la violencia; o del relato «Tía Lila» de Daniel Moyano, que permite al escritor riojano poder hablar de nuevo, y hablar del «horror», después del silencio ${ }^{7}$. Elisabeth Jelin explica así la incapaci- dad de comunicar, la imposibilidad de contar lo vivido-traumático:

Una de las características de las experiencias traumáticas es la masividad del impacto que provoca creando un hueco en la capacidad de «ser hablado» o contado. Se provoca un agujero en la capacidad de representación psíquica. Faltan las palabras, faltan los recuerdos. La memoria queda desarticulada y sólo aparecen huellas dolorosas, patologías y silencios. Lo traumático altera la temporalidad de otros procesos psíquicos y la memoria no los puede tomar, no puede recuperar ni transmitir o comunicar lo vivido (Jelin 8).

\section{Otros libros prohibidos}

El pueblo que no quería ser gris (1975), con texto de Beatriz Dourmec e ilustraciones de Ayax Barnes, fue otro de los libros prohibidos. Narra la historia de «un rey grande en un país chiquito. En el país chiquito vivían hombres, mujeres y niños. Pero el rey nunca hablaba con ellos, solamente les ordenaba...». Cuando ya no sabe qué más ordenar, se le ocurre la idea de que todos los habitantes del pueblo pinten su casa de color gris. Todos obedecen, «todos menos uno; uno que estaba sentado mirando el cielo, y vio pasar una paloma roja, azul y blanca», y decidió pintar de esos colores su casa. El resto de habitantes le imitan, hasta que todo el pueblo y sus alrededores deja de ser gris.

La presentación de un rey absoluto enfrentado de repente a una acción individual que consigue cambiar el contexto social, enlaza directamente esta narración con «El año verde» de Un elefante ocupa mucho espacio, en el que un muchacho toma una lata de pintura verde y hace llegar el año verde en el que todos serán felices siempre prometido por un poderoso rey sordo a las necesidades de su pueblo («iEl aire ya huele a verde! ¡Si todos juntos lo soñamos, si lo queremos, el año verde será el próximo!», Bornemann 81 ).

También fue objeto de prohibición $\mathrm{La}$ linea, publicado en 1974 por Beatriz Doumerc y Ayax Barnes, que recibió en 1975 el Premio Casa de las Américas. Volverá a reeditarse, en la colección Libros Álbum en el 2003 por Ediciones del Eclipse8.

Otros muchos libros fueron prohibidos, aunque no se han podido recuperar muchos datos y algunos de los textos: Los zapatos voladores de Margarita Belgrano, de la colección Cuentos del Chiribitil, un proyecto del CEAL;
Moyano relata así a Mempo Giardinelli su regreso a la escritura después del silencio: "Yo ya no creía en nada y le tenía miedo a volver a creer en la literatura. Además, habían pasado muchas cosas en el país, en mi vida, y bueno, yo no me considero un escritor realista y por lo tanto no sabía qué hacer. Pero estaba muy cargado. Así que un día me planté y le dije a Osvaldo: «Mira, yo no tengo más tías, y solamente sé escribir sobre mis tías, así que planto y se acabó». Entonces él me dijo: «Ah, bueno, yo tengo una, te la presto». Y siguiendo la broma, le pregunté cómo se llamaba y me dijo: "Se llamaba Lila y era preciosa; vive todavía». Me gustó ese nombre. Él empezó a contarme: «Mi tía Lila...» y yo lo interrumpí: "No, no me cuentes nada, porque si no, no voy a poder imaginar. Déjame ver si te cuento yo sobre la tía Lila». Y se produjo como un pinchazo en esa bolsa de angustias que yo tenía adentro, y por el agujerito empezó a salir el cuento, que ahora te regalo para la revista. En realidad yo no lo escribí, sino que estaba, se hizo solo, lo tenía guardado. Más aún, yo intenté no contarlo sino que sólo quise que sucedieran las cosas».

La edición censurada de Un elefante ocupa mucho espacio, de Bornemann, tenía también unas significativas ilustraciones de Ayax Barnes. Por su capacidad de hablar y sugerir a través de la imagen, las ilustraciones también fueron un señalado objeto de control por parte de la censura.

Una narrativa infantil y juvenil para la memoria

MARÍA BERMÚDEZ MARTÍNEZ 
En este artículo nos hemos cen trado exclusivamente en los relatos escritos por autores argentinos y publicados en Argentina.

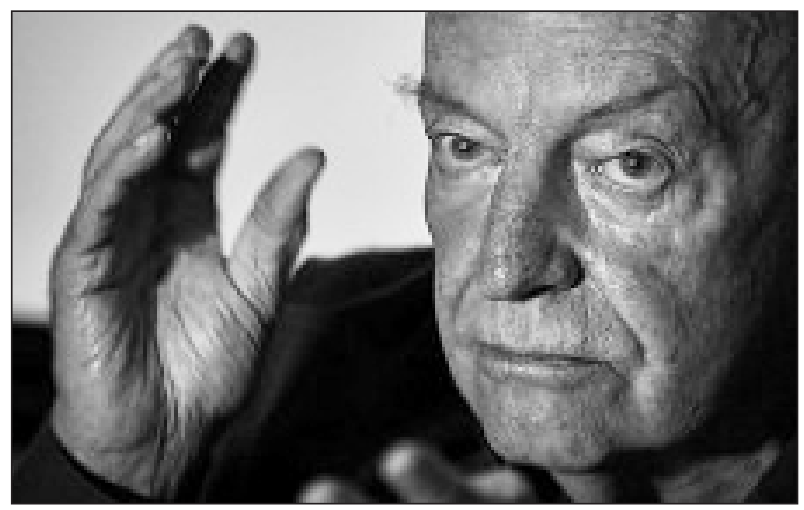

Eduardo Galeano, Brasilia, 2014. Foto: Rafael H. Barroso. Exupery 9 .
Dailán Kifki de María Elena Walsh; Jacinto de Graciela Cabal (Editorial Sudamericana. Buenos Aires, 1977) y otros textos internacionales como El principito de Antoine de Saint

\section{Recuperaciones de la Memoria}

En La piedra arde (1980), Eduardo Galeano nos presenta a un anciano, encorvado y cojo, con la nariz torcida y una cicatriz que le atraviesa la mejilla, con apenas pelo y sin dientes. Cuando el niño Carasucia le ofrece al buen anciano romper la piedra mágica que le devolverá la juventud y borrará sus cica-

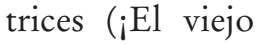
bailará como un trompo y saltará como una pulga y volará como un pájaro! ¡No volverá a toser! ¡Tendrá las piernas sanas y una cara sin tajos y una boca con todos los dientes!, 10), el viejo le responde, relatando su historia:

-Estos dientes no se cayeron solos. Me los arrancaron a golpes. Esta cicatriz que me corta la cara, no viene de un accidente. Los pulmones... La pierna... Rompí esta pierna cuando me escapé de la cárcel, porque era muy alto el muro y había vidrios abajo. Hay otras marcas, también, que no puedes ver. Marcas que tengo en el cuerpo y no solamente en el cuerpo y que nadie puede ver.

[...]

-Si parto la piedra, estas marcas se borrarán. Pero estas marcas son mis documentos, ¿comprendes? Mis documentos de identidad. Me miro al espejo y digo: «Ése soy yo», y no siento lástima de mí. Yo luché mucho tiempo. La lucha por la libertad es una lucha de nunca acabar. Ahora hay otros que luchan, allá lejos, como yo he luchado. Mi tierra y mi gente no son libres todavía. ¿Comprendes? Yo no quiero olvidar. No parto la piedra porque sería una traición (18-20).

El relato de Galeano es un texto referente de una narrativa de la memoria que recupera la huella de un pasado histórico traumático pero necesario para afrontar el presente y dibujar un futuro desde la experiencia vivida. En el mismo sentido podemos leer La composición de Skármeta, otro texto que recupera la memoria de las dictaduras del cono sur. Sin referencias espaciales que nos permitan vincular la situación narrada específicamente a la dictadura chilena de Pinochet, el texto de Skármeta recrea el asfixiante clima de aquella y otras dictaduras como las sufridas por Argentina, Uruguay o Paraguay en la segunda mitad del pasado siglo: censura, terror, incomunicación, control absoluto sobre las vidas individuales y las relaciones sociales... Desde la mirada de un niño, Skármeta recrea ese clima demostrando que sî se puede hablar, que no existen temas tabú en la literatura para niños y que la clave está en cómo narrar esa historia. Con un lenguaje lírico, aunque también preciso y directo, muestra las inquietudes de niño hacia la realidad históricosocial y la construcción de una posición ante ella, dándole la posibilidad de actuar.

En el ámbito de la literatura infantil argentina podemos referirnos a textos como el relato «Los desmaravilladores» de Elsa Bornemann, incluido en el libro de relatos homónimo (1991), que hace memoria de la dictadura militar argentina tematizando la desaparición de personas y adopción de niños durante el período. Una niña de entre 13 y 16 años que escribe bajo el pseudónimo de Humo envía un relato a un concurso de relatos históricos organizado por la «Academia Nacional de Historia de la República de Sudaquia». El relato enviado al certamen pone sobre la mesa algunas cuestiones centrales para la reflexión: el concepto de «historia» desde la perspectiva infantil/juvenil («ella no se olvidaba de que aún éramos niños y que lo que había acaecido doce o quince años atrás también formaba parte de la historia. De una historia reciente para los adultos - por supuesto- pero ocurrida cuando no habíamos nacido y - por lo mismo - tan lejana con la que se reproduce en los manuales»); la atmósfera de represión y violencia del período («No transcurría una semana sin que se difundieran comunicados prohibiendo esto, aquello y lo de más allá también, o proclamas incitando al caos; sin que estallaran artefactos explosivos en cualquier parte; sin que se produjeran sangrientos enfrentamientos entre «los desmaravilladores»); y la situación - eje de la trama - de secuestro y desaparición de personas ( «Decenas, cientos, miles de personas fueron como evaporadas... Miles y miles de las que sus familias no volvieron a tener noticias ni, en muchísimos casos, a enterarse de porqué 
de sus desapariciones. Como aspirados por una perfecta máquina de volatizar niños y bebés también»). El relato escrito por Humo, una de esas niñas nacidas en cautiverio tras la inenarrable suerte corrida por sus padres a manos de los «desmaravilladores» en el poder, compara la situación con «una excelente novela de terror».

Es interesante resaltar que si bien textos como los citados refieren de manera más o menos directa esa historia reciente, hay otros textos que, sin referencias directas, a través de las atmósferas recreadas, hablan - como ya apuntamos - sin hablar. A ello se ha referido en alguna ocasión Laura Devetach, llamando la atención de la crítica sobre «las marcas de la historia en todos los que escribimos durante esas épocas» (Devetach, "Autobiografía») y en este sentido se construye también, según nos explica Ana Garralón, la interpretación que hace Cristina Colombo acerca del auge del género de terror en la Argentina de los años ochenta, refiriéndose al libro de Elsa Bornemann Socorro o a textos como Irulana y el ogromonte (un cuento de mucho miedo) de Graciela Montes:

Estoy persuadida de que en estos relatos de terror aparecen los verdaderos fantasmas que han estado y aún están rondándonos desde la reciente historia argentina: la crueldad, el sadismo, desapariciones, secuestros, terrorismo, monstruos que se devoran a sí mismos, pánico, complicidad en el silencio, muerte y desolación (citado por Garralón 42).

Si bien la llegada de la democracia supuso un gran despegue para la literatura infantil y juvenil en Argentina (con proliferación de sellos editoriales, colecciones, instituciones de fomento de la literatura y la lectura....), tendremos que esperar más de una década tras la vuelta de la democracia, para encontrarnos con textos que recuperan la memoria del proceso para un lector juvenil, como Cruzar la noche de Alicia Barberis (1995), Los sapos de la memoria, de Graciela Bialet (1997), El mar y la serpiente de Paula Bombara (2005), entre otros. Entre estas recreaciones ficcionales del período que comienzan a verbalizar de manera directa esa historia, la temática de la desaparición de personas y las situaciones de secuestro y adopciones de niños, son las más frecuentes en la literatura juvenil argentina. Se trata de relatos que van conformando una escritura de la memoria si bien, en ocasiones, desde planteamientos un tanto arquetípicos, como denuncia - sin discutir la eficacia narrativa de los textos y el placer que produce su lecturaFernández Felsenthal. Si bien en ocasiones prima la fórmula, con estructuras arquetípicas de buenos y malos y reiteración de determinados temas y visiones, los textos citados

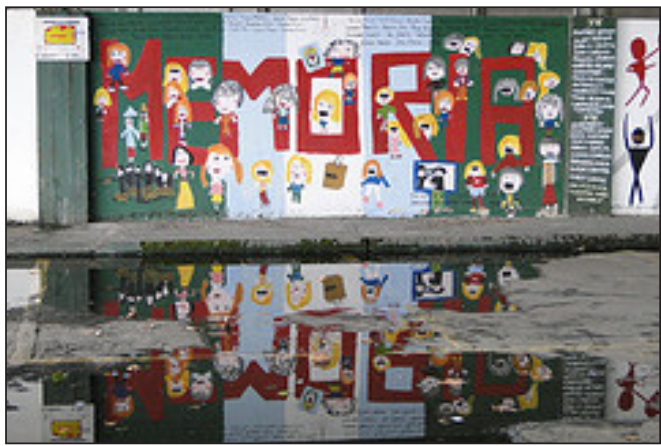

Centro clandestino de detención El Olimpo, Buenos Aires. Foto: Adam Jones. destacan también por su construcción narrativa, por su posicionamiento enfrentado a la «doxa» del Poder y, sobre todo, por poner sobre la mesa un asunto crucial para la literatura infantil y juvenil, el cruce de dos posturas históricas sobre el niño y la infancia: por un lado, la esfera de protección hacia el menor (los «corrales» de los que hablaba Graciela Montes) y la consideración del niño/adolescente como sujeto activo de derecho (véase, en este sentido, la lectura realizada por Scerbo de El mar y la serpiente de Paula Bombara).

Volvemos así al planteamiento inicial sobre el funcionamiento del poder en los discursos y la circulación del material cultural, en este caso una incipiente narrativa que nos ofrece marcos interpretativos para la comprensión del pasado y la formulación del proyectos de futuro en el marco específico de una literatura infantil y juvenil cuyo objetivo, en palabras de Felsenthal, «es, y será siempre innegable: los individuos en formación» (que no, matizamos, la formación de los individuos); lo cual pone de manifiesto también las siempre necesarias tensas relaciones de dicha literatura con la institución escolar $y$, en definitiva, con el poder.

De ahí la importancia de desplegar esas miradas que recuperen, polifónicamente, esa memoria histórica para los niños y jóvenes - en un mundo actual en el que rigen otras fuerzas de poder y otros «corrales» como diría Montes - y la relevancia que en dichas miradas debe jugar la literatura misma, sus leyes y sus juegos que, evidentemente, no son los de la historia.

\section{Bibliografía}

barberis, Alicia. Cruzar la noche. Buenos Aires: Colihue, 1995.

Bialet, Graciela. Los sapos de la memoria. Córdoba: Op Oloop Ediciones, 1997.
Una narrativa infantil y juvenil para la memoria
MARÍA BERMÚDEZ MARTÍNEZ 
Bombara, Paula. El mar y la serpiente. Buenos Aires: Norma, 2005.

Bornemann, Elsa. Un elefante ocupa mucho espacio. Madrid: Santillana, 2005 (1 $1^{\text {a }}$ ed. 1975).

Cabal, Graciela. «Centro Editor de América Latina: Libros que ardieron durante días», Imaginaria, $\mathrm{n}^{\circ} 48$ (Los libros infantiles probibidos por la dictadura militar en Argentina. Fragmentos del fascículo Un golpe a los libros 1976-1983), 2001. Disponible en http://www.imaginaria.com.ar/04/8/ prohibidos.htm

Carranza, Marcela. «La literatura al servicio de los valores, o cómo conjurar el peligro de la literatura", Imaginaria, 181 (2006). Disponible en http://www.imaginaria.com. ar/18/1/literatura-y-valores.htm

Devetach, Laura. "Autobiografía». Imaginaria, $\mathrm{n}^{\circ} 21$ (2000). Disponible en http://www. imaginaria.com.ar/02/1/devetach1.htm

Devetach, Laura. La torre de cubos. Buenos Aires: Colihue, 2006 ( $1^{\circ} \mathrm{ed}$ e 1966).

Devetach, Laura. «Primer cubo: algunas ideas sobre La torre de cubos». Imaginaria, $\mathrm{n}^{\circ} 176$ (Una torre de cubos para armar en libertad) (2006). Disponible en http://www.imaginaria.com.ar/17/6/la-torre-de-cubos.htm

Fernández Felsenthal, Andrea. «La literatura infantil y juvenil (LIJ) sobre la dictadura militar en Argentina y en Latinoamérica», III Congreso Ibérico de Literatura Infantil y Juvenil, Universitat Politècnica de València, 27 al 30 de junio de 2005. Disponible en http://www.aepv.net/miniwebs/congresoLiteraturaInfantil/comunica/C1.\%20 LIT.\%20INFANTIL.\%20pdf.pdf

Galeano, Eduardo. La piedra arde. Salamanca: Lóguez Ediciones, 1993.

Garralón, Ana. «Temas y modos de la Literatura infantil latinoamericana», Cuadernos Hispanoamericanos, 776 (2015): 33-47.

Gociol, Judith (coord.). Un golpe a los libros (1976-1983). Buenos Aires: Secretaría de Cultura del Gobierno de la Ciudad de Buenos Aires, 2001. Fragmentos del fascículo en Imaginaria, $\mathrm{n}^{\circ} 48$ (Los libros infantiles probibidos por la dictadura militar en $\mathrm{Ar}$ gentina. Fragmentos del fascículo Un golpe a los libros 1976-1983) (2001).

Invernizzi, Hernán y Gociol, Judith. Un golpe a los libros: represión a la cultura durante la última dictadura militar, Buenos Aires: Eudeba, 2007.

Jelin, Elizabeth. «Memorias en conflicto». Revista Puentes, 1:1 (2000): 6-13.
Machado, Ana $\mathrm{M}^{\mathrm{a}}$ y Montes, Graciela. Literatura infantil. Creación, censura y resistencia, Buenos Aires: Sudamericana, 2003.

Machado, Ana $\mathrm{M}^{\mathrm{a}}$. «Prólogo». Graciela Montes, El corral de la infancia, México: FCE, 2001: 7-10.

Mariño, Ricardo. «El terreno donde crece la literatura infantil», La Mancha, 8 (1999).

Montes, Graciela. El corral de la infancia. México: FCE, 2001.

Moyano, Daniel. «Al cuento hay que tocarlo en un buen violín y bien tocado». Mempo Giardinelli, Asi se escribe un cuento, Barcelona: Punto de Lectura, 2002, 218-232.

Nofal, Rosana. «Los domicilios de la memoria en la literatura infantil argentina: un aporte a la discusión», Espéculo. Revista de estudios literarios, 23 (2003). Disponible en http://www.ucm.es/info/especulo/numero23/mem_arge.html

Raggio, Sandra (coord.) y Oliva, Josefina. La censura en la literatura infantil y juvenil durante la última dictadura. La Plata: Comisión Provincial por la Memoria, s.f. Disponible en http://www.comisionporlamemoria.org/investigacionyensenanza/ dossiers/dossierlibros.pdf

Rodari, Gianni. «La imaginación en la literatura infantil», Imaginaria, 125 (2004). Disponible en http://www.imaginaria.com. ar/12/5/rodari2.htm

Rodríguez Paoletti, Claudio. «Propuesta Didáctica. Libros: memoria con futuro», La Educación en nuestras manos, 75, (2006).

Rufa, Fernando. «La censura y quema de libros durante la dictadura militar». Proyecto Sur Córdoba [Blog]. 2009. Disponible en http://juventudproyectosurcordoba.blogspot.com.es/2009/12/la-censura-y-quemade-libros-durante-la.html

Scerbo, Ignacio, «Memoria de los desaparecidos en la literatura para jóvenes. La nouvelle El mar y la serpiente de Paula Bombara». Afuera. Estudios de critica cultural, II:12 (2012). Disponible en http://www.revistaafuera.com/articulo. php? id $=235 \&$ nro $=12 \#$ t6

Skármeta, Antonio. La composición. Caracas: Ekaré, 2000.

Sotelo, Roberto. «Introducción». Imaginaria, 176 (2006).
Fecha de recepción: 30/07/2015

Fecha de aceptación: 1/10/2015 